\title{
Configurational disorder effects on adatom mobilities on Ti1-xAlxN(001) surfaces from first principles
}

\author{
Björn Alling, Peter Steneget, Christopher Tholander, Ferenc Tasnádi, Ivan Petrov, \\ Joseph E Greene and Lars Hultman
}

\section{Linköping University Post Print}

\begin{abstract}
N.B.: When citing this work, cite the original article.
\end{abstract}
Original Publication:

Björn Alling, Peter Steneget, Christopher Tholander, Ferenc Tasnádi, Ivan Petrov, Joseph E Greene and Lars Hultman, Configurational disorder effects on adatom mobilities on Ti1xAlxN(001) surfaces from first principles, 2012, Physical Review B. Condensed Matter and Materials Physics, (85), 24, 245422.

http://dx.doi.org/10.1103/PhysRevB.85.245422

Copyright: American Physical Society http://www.aps.org/

Postprint available at: Linköping University Electronic Press http://urn.kb.se/resolve?urn=urn:nbn:se:liu:diva-78822 


\title{
Configurational disorder effects on adatom mobilities on $\mathrm{Ti}_{1-x} \mathrm{Al}_{x} \mathbf{N}(001)$ surfaces from first principles
}

\author{
B. Alling, ${ }^{1,}{ }^{*}$ P. Steneteg, ${ }^{1}$ C. Tholander,${ }^{1}$ F. Tasnádi, ${ }^{1}$ I. Petrov, ${ }^{1,2}$ J. E. Greene, ${ }^{1,2}$ and L. Hultman ${ }^{1}$ \\ ${ }^{1}$ Department of Physics, Chemistry and Biology (IFM), Linköping University, SE-581 83 Linköping, Sweden \\ ${ }^{2}$ Frederick Seitz Materials Research Laboratory and the Materials Science Department, University of Illinois at Urbana-Champaign, Urbana, \\ Illinois 61801, USA
}

(Received 23 February 2012; revised manuscript received 24 May 2012; published 11 June 2012)

\begin{abstract}
We use metastable $\mathrm{NaCl}$-structure $\mathrm{Ti}_{0.5} \mathrm{Al}_{0.5} \mathrm{~N}$ alloys to probe effects of configurational disorder on adatom surface diffusion dynamics which control phase stability and nanostructural evolution during film growth. Firstprinciples calculations were employed to obtain potential energy maps of $\mathrm{Ti}$ and $\mathrm{Al}$ adsorption on an ordered $\mathrm{TiN}(001)$ reference surface and a disordered $\mathrm{Ti}_{0.5} \mathrm{Al}_{0.5} \mathrm{~N}(001)$ solid-solution surface. The energetics of adatom migration on these surfaces are determined and compared in order to isolate effects of configurational disorder. The results show that alloy surface disorder dramatically reduces Ti adatom mobilities. Al adatoms, in distinct contrast, experience only small disorder-induced differences in migration dynamics.
\end{abstract}

DOI: 10.1103/PhysRevB.85.245422

PACS number(s): 68.43.Bc, 61.66.Dk, 68.35.bd, 68.35.Dv

\section{INTRODUCTION}

Thin film growth is a complex phenomenon controlled by the interplay of thermodynamics and kinetics. This complexity facilitates the synthesis of metastable phases, such as $\mathrm{Ti}_{1-x} \mathrm{Al}_{x} \mathrm{~N}$ alloys, which are not possible to obtain under equilibrium conditions; thus, broadening the range of available physical properties in materials design. Fundamental understanding of elementary growth processes such as adatom diffusion, which govern nanostructural and surface morphological evolution during thin film growth, can only be developed by detailed studies of their dynamics at the atomic scale. Research has mostly been carried out using elemental metals, as reviewed in Refs. 1 and 2. Much less is known about the atomic-scale dynamics of compound surfaces, and even less about configurationally disordered pseudobinary alloys which are presently replacing elemental and compound phases in several commercial applications.

Kodambaka et al. ${ }^{3}$ and Wall et al. ${ }^{4}$ used scanning tunneling microscopy to determine surface diffusion activation energies on low-index surfaces of TiN. However, due to the vast difference between experimental and adatom hopping time scales, determining diffusion pathways requires theoretical approaches via first-principles methods that are capable of providing clear atomistic representation on the picosecond time scale. Gall et al. ${ }^{5}$ employed first-principles calculations to show that the energy barrier for Ti adatom diffusion on TiN is much lower on the (001) than the (111) surface, leading to diffusional anisotropy.

Alloying TiN with AlN has been shown to alter surface reaction pathways controlling film texture and nanostructure. ${ }^{6-9}$ $\mathrm{Ti}_{1-x} \mathrm{Al}_{x} \mathrm{~N}$ alloys with $x \sim 0.5$, synthesized by physical vapor deposition (PVD) far from thermodynamic equilibrium, ${ }^{10}$ are commercially important for high-temperature oxidation ${ }^{11}$ and wear-resistant applications. ${ }^{6,12}$ Unfortunately, atomic-scale understanding of the growth of these important, and more intricate, materials systems is presently rudimentary as best. Surface diffusion on a metal alloy, the CuSn system in ordered configurations and in the dilute limit, ${ }^{13}$ has only recently been considered using first principles. However, it is well known that configurational disorder can have large impact on the physical properties of solid solutions. ${ }^{14}$ As an initial step in probing these latter effects, we begin by using cubic $\mathrm{Ti}_{1-x} \mathrm{Al}_{x} \mathrm{~N}(001)$ as a model system to investigate the role of configurational disorder in cation diffusitivities of importance for phase stability, surface morphology, and nanostructural evolution during growth.

\section{METHODOLOGY}

A. Calculational details

We employ first-principles calculations using the projector augmented wave method, ${ }^{15}$ as implemented in the Vienna $a b$ initio simulation package (VASP) ${ }^{16}$ to determine the energetics of cation adsorption and diffusion on ordered $\mathrm{TiN}(001)$ and configurationally disordered $\mathrm{Ti}_{0.5} \mathrm{Al}_{0.5} \mathrm{~N}(001)$ surfaces. Electronic exchange-correlation effects are modeled using the generalized gradient approximation. ${ }^{17}$ The plane-wave energy cutoff is set to $400 \mathrm{eV}$. We sample the Brillouin zone with a grid of $3 \times 3 \times 1 k$ points.

$\mathrm{TiN}(001)$, for reference, and $\mathrm{Ti}_{0.5} \mathrm{Al}_{0.5} \mathrm{~N}(001)$ surfaces are modeled using slabs with four layers of $3 \times 3$ in-plane conventional cells with 36 atoms per layer. Calculated equilibrium lattice parameters $a_{0}$ of bulk TiN, $4.255 \AA$, and $\mathrm{Ti}_{0.5} \mathrm{Al}_{0.5} \mathrm{~N}$, $4.179 \AA$ A, obtained previously, ${ }^{18}$ are employed. The vacuum layer above the surfaces corresponds to $5.5 a_{0}$. The adatoms are spin polarized, which is found to be important for $\mathrm{Ti}$ adatoms with its partially filled $3 d$ shell, but not for Al. To investigate diffusion on a configurationally disordered surface, the $\mathrm{Ti}_{0.5} \mathrm{Al}_{0.5} \mathrm{~N}(001)$ slab is modeled using the special quasirandom structure (SQS) method. ${ }^{19}$ We impose a homogenous layer concentration profile and minimize the correlation functions on the first six nearest-neighbor shells for the slab as a whole.

Convergence of diffusion barriers is tested with respect to the geometrical and numerical details of the calculations. In particular, we checked convergency with respect to the number of layers included in the slab, from three to eight, and the in-plane size of the supercell, from 16 to 36 atoms per layer. The impacts of a plane-wave energy cutoff between 300 and $600 \mathrm{eV}$, a denser $k$-point grid of $5 \times 5 \times 1$, and 
inclusion of $\mathrm{Ti} 3 p$ semicore states in the valence were tested. Furthermore, our primary potential energy surface approach was assessed using both nudged-elastic-band calculations and an extremely dense grid of sampling points. The results show that calculated energy barriers are within $0.04 \mathrm{eV}$ of the converged value, partly due to error cancellation between the effects of treating Ti semicore states as core and the limited number of layers; both of which are on the order of $0.08 \mathrm{eV}$, but with opposite signs. Errors from all other numerical and geometrical limitations of the calculations are significantly smaller.

\section{B. Modeling adatom mobilities}

The adatom adsorption energy $E_{\text {ads }}^{\mathrm{Al}, \mathrm{Ti}}(x, y)$ is calculated for $\mathrm{Ti}$ and $\mathrm{Al}$ adatoms as a function of positions $x$ and $y$ on both ordered $\mathrm{TiN}(001)$ and disordered $\mathrm{Ti}_{0.5} \mathrm{Al}_{0.5} \mathrm{~N}(001)$ surfaces as

$$
E_{\text {ads }}^{\mathrm{Al}, \mathrm{Ti}}(x, y)=E_{\text {slab+ad }}^{\mathrm{Al}, \mathrm{Ti}}(x, y)-E_{\text {slab }}-E_{\text {atom }}^{\mathrm{Al}, \mathrm{Ti}} .
$$

$E_{\text {slab+ad }}^{\mathrm{Al}, \mathrm{Ti}}$ is the energy of the slab with an adatom at $(x, y), E_{\text {slab }}$ is the energy of the pure slab with no adatoms, and $E_{\text {atom }}^{\mathrm{Al}, \mathrm{Ti}}$ is the energy of an isolated $\mathrm{Al}$ or $\mathrm{Ti}$ atom in vacuum. We use a fine grid of sampling points, $\Delta x=\Delta y=0.05 a_{0}$. In each calculation corresponding to a point in the $x y$ plane, the adatom is fixed within the plane and relaxed out of plane. The upper two layers of the slab are fully relaxed, while the lower two layers are stationary. A periodic polynomial interpolation between the calculated points is used to obtain a smooth potential energy surface (PES).

Transition-state theory within a probabilistic approach is used to determine the mobilities of independent adatoms on the obtained PES. The probability at each time step for a Ti or $\mathrm{Al}$ adatom at site $i$ to jump to a neighboring site $j$ is calculated as

$$
\Gamma_{i j}=v_{0} \exp \left(\frac{-\Delta E_{i j}}{k_{B} T}\right),
$$

where $\Delta E_{i j}=\left(E_{i j}-E_{i}\right)$ is the difference between the adsorption energy in the local minima $i$ and at the saddle point defining the barrier height $E_{i j}$ between sites $i$ and $j$. The temperature $T$ is $800 \mathrm{~K}$, a representative value for PVD growth of transition-metal nitride thin films. For convenience, we choose the attempt frequency $v_{0}$ to be the same for $\mathrm{Ti}$ and $\mathrm{Al}$ on both $\mathrm{TiN}(001)$ and $\mathrm{Ti}_{0.5} \mathrm{Al}_{0.5} \mathrm{~N}(001)$ surfaces, but note that $\mathrm{Al}$ adatoms should have a slightly higher attempt frequency than Ti due to their lower mass. Since we are only investigating individual adatom diffusion, and not adatom interactions, we work with the adatom probability densities $n_{i}(t)$ at site $i$ at time $t$ rather then discrete individual particles. This corresponds to an ensemble average of a large number of individual cases. Given any set of initial conditions for $n_{i}(t)$, they can be propagated using Eq. (2) to monitor the development of adatom density in time. To study the dynamics of more complex adsorbed species over long time scales, classical molecular dynamics is an alternative. ${ }^{20}$

To simulate (001) grain surfaces, circles of radii $8.5 a_{0}$ are cut from $7 \times 7$ grids of the obtained $\mathrm{TiN}(001)$ or $\mathrm{Ti}_{0.5} \mathrm{Al}_{0.5} \mathrm{~N}(001)$ PESs. The SQS supercell is based on periodic boundary conditions and designed to describe moderately short-ranged properties of random alloys, such as configurational energies. Thus, one could suspect that diffusion, which is an inherently long-range phenomenon, would be affected by the periodicity even if local energy minima and energy barriers are well described. We test the impact of the SQS periodicity and go beyond it with the following approach: when creating the simulated grain for the disordered surface, we apply, in addition to standard periodic repetition, a rotation procedure in which the SQS PESs forming the simulated grain are randomly rotated by $0^{\circ}, 90^{\circ}, 180^{\circ}$, or $270^{\circ}$ before being joined smoothly. In rare cases for which the rotation induces a barrier height at the boundary that is lower than the highest minimum surrounding it, it is replaced with a barrier height according to $E_{i j}=\frac{1}{2}\left(E_{i}+E_{j}\right)+\bar{\gamma}$ where $\bar{\gamma}$ is the mean of the differences $\gamma_{i j}=E_{i j}-\frac{1}{2}\left(E_{i}+E_{j}\right)$ over the entire SQS PES.

The most probable $\mathrm{Al}$ and $\mathrm{Ti}$ diffusion paths across a simulated grain surface can then be identified by the following approach: We impose a constant probability density of adatoms at the centers of the circular grains, and then propagate the probability density using Eq. (2). Adatoms crossing the grain boundary are not allowed to cross back. Thus, we obtain a net adatom probability flow $F_{i j}$ between sites $i$ and $j$ from the center of the grain outward,

$$
F_{i j}=n_{i} \Gamma_{i j}-n_{j} \Gamma_{j i},
$$

where the largest flow should take place along the most favorable diffusion paths.

\section{RESULTS}

\section{A. Adsorption potential energy surfaces}

Adsorption potential energy surfaces for $\mathrm{Al}$ and $\mathrm{Ti}$ atoms on $\mathrm{TiN}(001)$ and $\mathrm{Ti}_{0.5} \mathrm{Al}_{0.5} \mathrm{~N}(001)$ surfaces are shown in Figs. 1(a)-1(d). The most favorable sites for $\mathrm{Al}$ adatoms on both surfaces are directly above $\mathrm{N}$ atoms at bulk cation positions. For $\mathrm{Al}$ on $\mathrm{TiN}(001)$, Fig. $1(\mathrm{a}), E_{\mathrm{ads}}^{\mathrm{Al}}$ is $-2.54 \mathrm{eV}$. On $\mathrm{Ti}_{0.5} \mathrm{Al}_{0.5} \mathrm{~N}(001)$, Fig. $1(\mathrm{~b}), E_{\text {ads }}^{\mathrm{Al}}$ varies from -2.39 to $-1.52 \mathrm{eV}$ on bulk cation sites depending on the local environment. Ti adatoms have two stable adsorption sites: fourfold hollows, surrounded by two $\mathrm{N}$ and two metal atoms, and the bulk site on-top N. For TiN(001), Fig. 1(c), $E_{\text {ads }}^{\mathrm{Ti}}=$ $-3.50 \mathrm{eV}$ in the hollow site and $-3.27 \mathrm{eV}$ above $\mathrm{N}$. On the alloy surface, Fig. 1(d), $E_{\text {ads }}^{\mathrm{Ti}}$ varies from -3.42 to $-2.58 \mathrm{eV}$ in the hollow sites and -3.23 to $-2.67 \mathrm{eV}$ in on-top sites. Al-rich environments are much less favorable for both $\mathrm{Al}$ and $\mathrm{Ti}$ adatoms as can be seen in the lower right regions of Figs. 1(b) and 1(d). The overall preferred sites for $\mathrm{Ti}$ on $\mathrm{Ti}_{0.5} \mathrm{Al}_{0.5} \mathrm{~N}(001)$ are fourfold hollow positions with one $\mathrm{Ti}$ and one Al nearest metal neighbors; not two Ti atoms as might have been expected. For comparison, we have also calculated $E_{\text {ads }}^{\mathrm{Al}, \mathrm{Ti}}$ on the (001) surface of $\mathrm{NaCl}$-structure $B 1 \mathrm{AlN}$, using the previously obtained lattice spacing $a_{0}=4.069 .{ }^{18}$ In this case $E_{\mathrm{ads}}^{\mathrm{Al}}$ is $-1.32 \mathrm{eV}$ and $E_{\mathrm{ads}}^{\mathrm{Ti}}$ is $-2.47 \mathrm{eV}$ on the most favorable sites.

To analyze the origin of the spread in adsorption energies for $\mathrm{Ti}$ adatoms in stable sites on $\mathrm{Ti}_{0.5} \mathrm{Al}_{0.5} \mathrm{~N}(001)$, we show in Fig. 2 the calculated electronic density of states (DOS) for the $\mathrm{Ti}$ adatom in three different stable hollow-site positions: (a) the most favorable hollow site coordinated with one $\mathrm{Ti}$, 

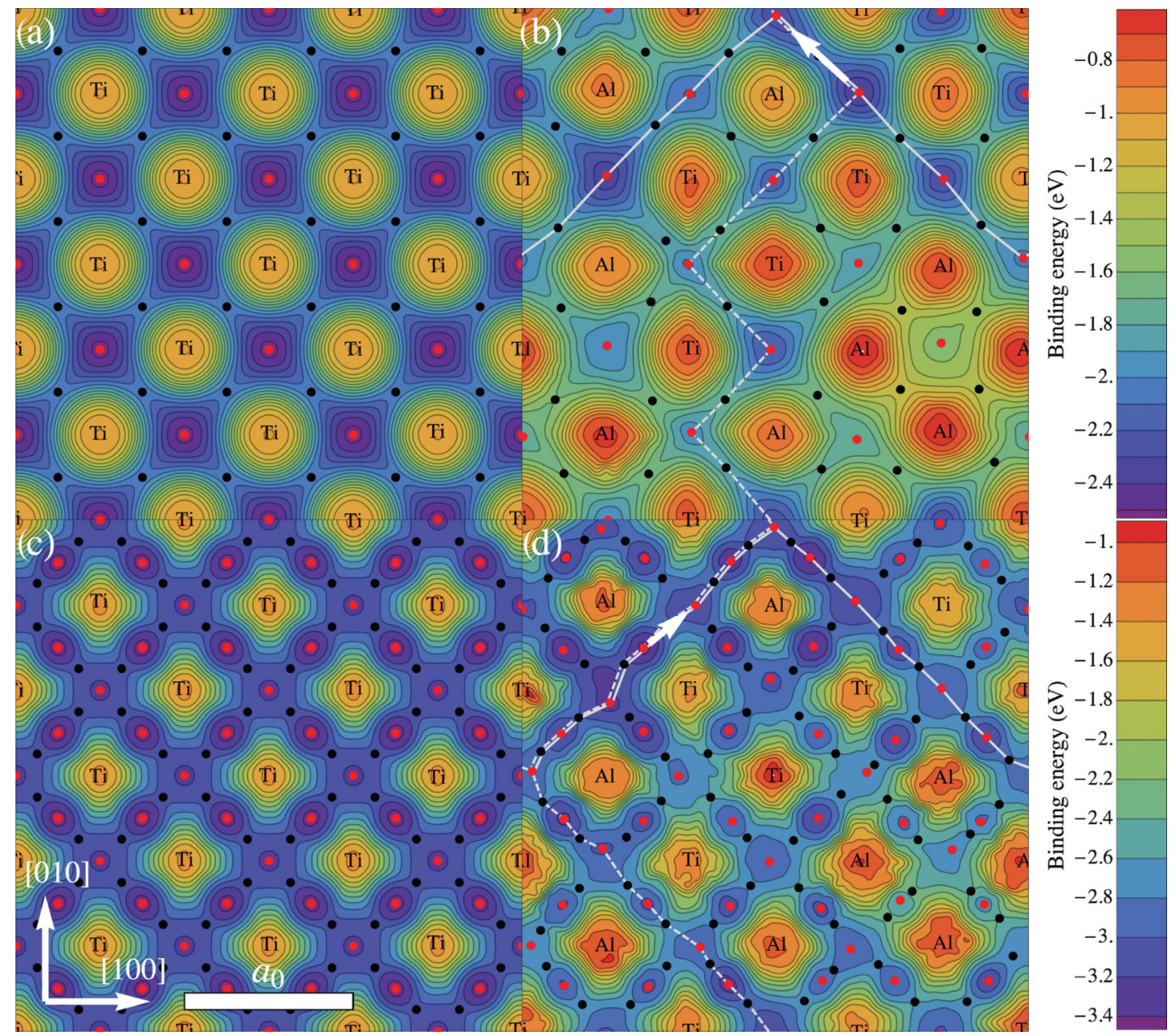

FIG. 1. (Color online) Adsorption energy surface for (a) an $\mathrm{Al}$ adatom on $\mathrm{TiN}(001)$, (b) an $\mathrm{Al}$ adatom on $\mathrm{Ti}_{0.5} \mathrm{Al}_{0.5} \mathrm{~N}(001)$, (c) a Ti adatom on $\mathrm{TiN}(001)$, and (d) a Ti adatom on $\mathrm{Ti}_{0.5} \mathrm{Al}_{0.5} \mathrm{~N}(001)$. Local minima are marked with red dots, while black dots indicate saddle point barrier positions. White lines, solid and dashed, shows preferred paths for diffusion on the disordered surfaces.

one $\mathrm{Al}$, and two $\mathrm{N}$ surface atoms, (b) a hollow site coordinated with two Ti and two $\mathrm{N}$ surface atoms, and (c) a hollow site coordinated by two $\mathrm{Al}$ and two $\mathrm{N}$ surface atoms. It is clear that the main peak of the occupied portion of the adatom $d$ band is shifted to lower energies for the most favorable Ti-Al coordinated site in Fig. 2(a), compared to corresponding results for the less favorable sites shown in Figs. 2(b) and 2(c). This can be understood in the following way: It is unfavorable for Ti surface atoms to have $\mathrm{Al}$ metal nearest neighbors since this implies a loss of Ti-Ti bonds, originating from $3 d t_{2 g}$ orbital hybridization, as has been discussed in detail for bulk $\mathrm{Ti}_{1-x} \mathrm{Al}_{x} \mathrm{~N}^{21,22}$ This results in a dangling-bond-type electronic structure, in addition to surface-induced distortions, and the dangling bond can bind strongly to a Ti adatom placed at the corresponding hollow site. In contrast, for Ti-Ti coordinated hollow sites, this feature is not present to attract the adatom. In $\mathrm{Al}-\mathrm{Al}$ coordinated sites, the surface metal atoms have no $3 d$ electrons to form strong bonds with the Ti adatom.

\section{B. Adatom mobilities}

The next step is to quantify the impact of disorder on adatom mobilities, and we begin by identifying the most favorable paths for diffusion across $\mathrm{TiN}(001)$ and $\mathrm{Ti}_{0.5} \mathrm{Al}_{0.5} \mathrm{~N}(001)$ surfaces. We use transition-state theory and the probabilistic procedure described in Sec. II B. Figures 3 and 4 show for $\mathrm{Al}$ and $\mathrm{Ti}$ adatoms, respectively, the steady-state net adatom probability flow $F_{i j}$ from the center to the boundary of the simulated (001) grains. In each figure, panel (a) shows the results on pure $\operatorname{TiN}(001)$, panel (b) the results for the periodically repeated $\mathrm{Ti}_{0.5} \mathrm{Al}_{0.5} \mathrm{~N}(001) \mathrm{SQS}$ PESs, and panel (c) the results for the randomly rotated $\mathrm{Ti}_{0.5} \mathrm{Al}_{0.5} \mathrm{~N}(001) \mathrm{SQS}$ PESs. The directions of the rotations are illustrated with arrows in the insets of panels (b) and (c). In each plot, the grayscale intensity is proportional to $F_{i j}$.

From the results in Fig. 3(a), it is clear that the flow of $\mathrm{Al}$ adatoms across the ordered $\mathrm{TiN}(001)$ surface is symmetric and utilizes all in-plane [110] paths. However, the flow of $\mathrm{Al}$ atoms across $\mathrm{Ti}_{0.5} \mathrm{Al}_{0.5} \mathrm{~N}(001)$, Figs. 3(b) and 3(c), is almost completely absent in the energetically least favorable regions. Instead, most diffusion takes place along special paths which are identified on the SQS surface in Fig. 1(b) by white solid and dashed lines corresponding approximately to connections among the most favorable local energy minima. The diffusion patterns are qualitatively similar for Ti adatoms as shown in Fig. 4, with corresponding preferred paths marked in Fig. 1(d). 


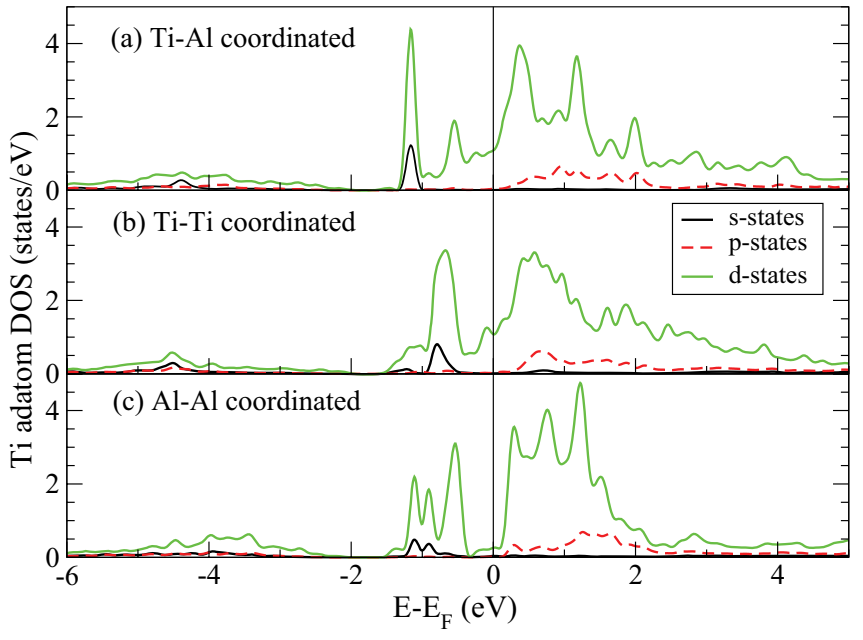

FIG. 2. (Color online) Calculated electronic densities of states for a $\mathrm{Ti}$ adatom in three different hollow sites on $\mathrm{Ti}_{0.5} \mathrm{Al}_{0.5} \mathrm{~N}(001)$ coordinated, in addition to two $\mathrm{N}$ atoms, with (a) one $\mathrm{Ti}$ and one $\mathrm{Al}$ atom, (b) two $\mathrm{Ti}$ atoms, and (c) two $\mathrm{Al}$ atoms.

When comparing the periodically repeated and randomly rotated SQS PES surfaces, Figs. 4(b) and 4(c), one can identify that the periodicity in the former case induces preferred diffusion paths that are connected across the entire grain. This is most apparent in Fig. 4(b) in which Ti adatoms exhibit anisotropic migration behavior with a preferred horizontal diffusion direction. In Figs. 3(c) and 4(c), the rotations of the SQS PESs disconnect the preferred diffusion paths and restore diffusion isotropy.

Next, we determine the time scales of adatom diffusion on the two surfaces. Figure 5 is a plot of the probability as a function of time that adatoms, individually placed at randomly chosen sites close to the center of a circular grain, have not yet reached the grain boundary. On the pure $\mathrm{TiN}(001)$ surface, $\mathrm{Al}$ and Ti adatoms show similar behavior as the somewhat higher barriers for $\mathrm{Al}$ diffusion are compensated by $\mathrm{Ti}$ adatoms having three times as many local minima for a given grain size. The striking result, however, is that Ti adatoms diffuse much more slowly on $\mathrm{Ti}_{0.5} \mathrm{Al}_{0.5} \mathrm{~N}(001)$ than on $\mathrm{TiN}(001)$. In contrast, the rates for $\mathrm{Al}$ adatom diffusion are nearly equal on the two surfaces and essentially indistinguishable. Whether the SQS PESs are periodically repeated (thick black lines in Fig. 5) or randomly rotated in the simulation of the grain (several thin black lines in Fig. 5, representing different sets of rotations) does not have a large impact on diffusion time scales for either $\mathrm{Al}$ or $\mathrm{Ti}$ adatoms. That is, the net conclusion remains the same: $\mathrm{Ti}_{0.5} \mathrm{Al}_{0.5} \mathrm{~N}(001)$ alloy-induced surface disorder dramatically reduces Ti adatom mobilities with only a small effect on Al mobilities.

\section{Discussion}

Since both $\mathrm{Ti}$ and $\mathrm{Al}$ adatoms diffuse predominantly along preferential paths on the disordered TiAlN(001) surface, irrespective of whether or not those paths are connected globally due to periodic boundary conditions, mobility differences are, primarily, explained by differences in energy profiles along these paths.
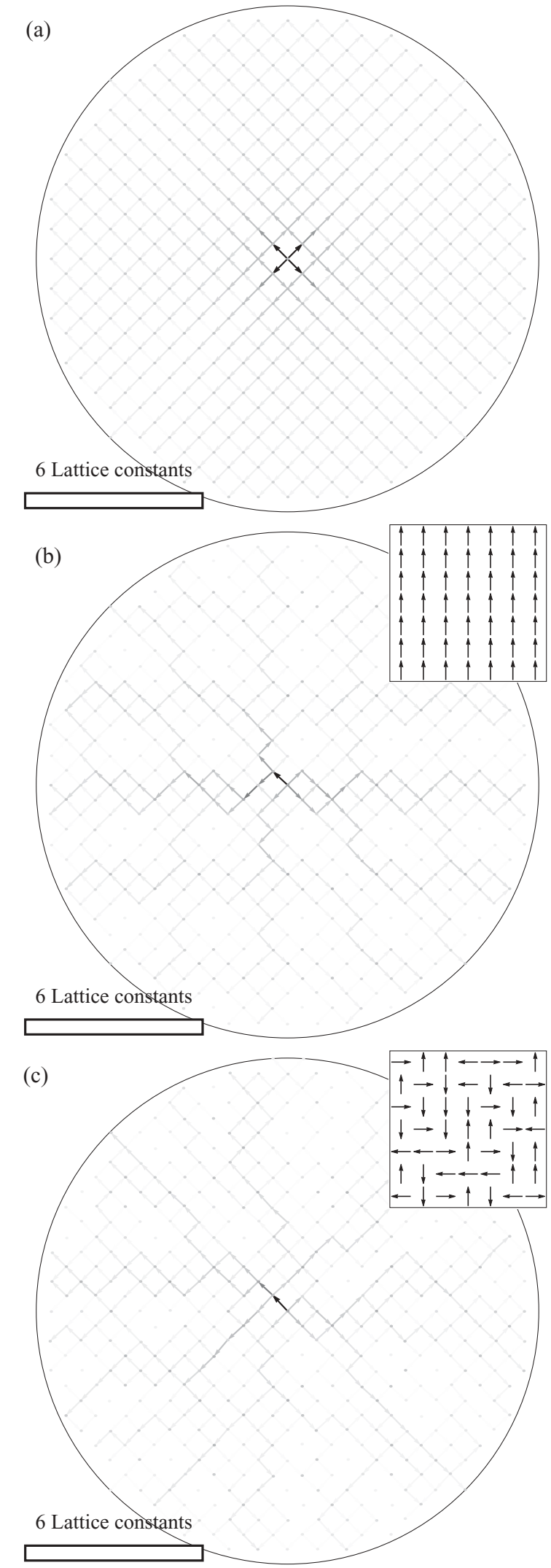

FIG. 3. Al adatom diffusion paths from the center to the edge of (001) surfaces of (a) TiN, (b) disordered $\mathrm{Ti}_{0.5} \mathrm{Al}_{0.5} \mathrm{~N}$ modeled with periodically repeated SQS PES cells, and (c) disordered $\mathrm{Ti}_{0.5} \mathrm{Al}_{0.5} \mathrm{~N}$ modeled with SQS PES cells randomly rotated by $0^{\circ}, 90^{\circ}, 180^{\circ}$, or $270^{\circ}$, as defined by the arrows in the insets. 

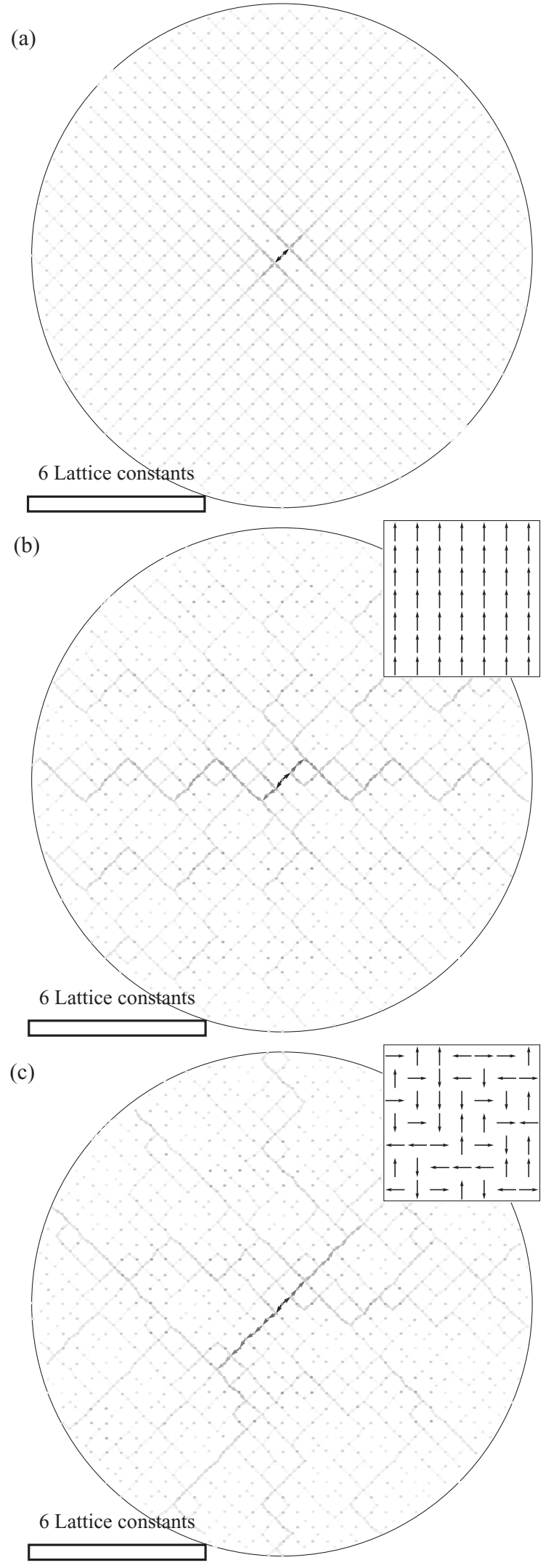

FIG. 4. Ti adatom diffusion paths from the center to the edge of (001) surfaces of (a) TiN, (b) disordered $\mathrm{Ti}_{0.5} \mathrm{Al}_{0.5} \mathrm{~N}$ modeled with periodically repeated SQS PES cells, and (c) disordered $\mathrm{Ti}_{0.5} \mathrm{Al}_{0.5} \mathrm{~N}$ modeled with SQS PES cells randomly rotated by $0^{\circ}, 90^{\circ}, 180^{\circ}$, or $270^{\circ}$, as defined by the arrows in the insets.

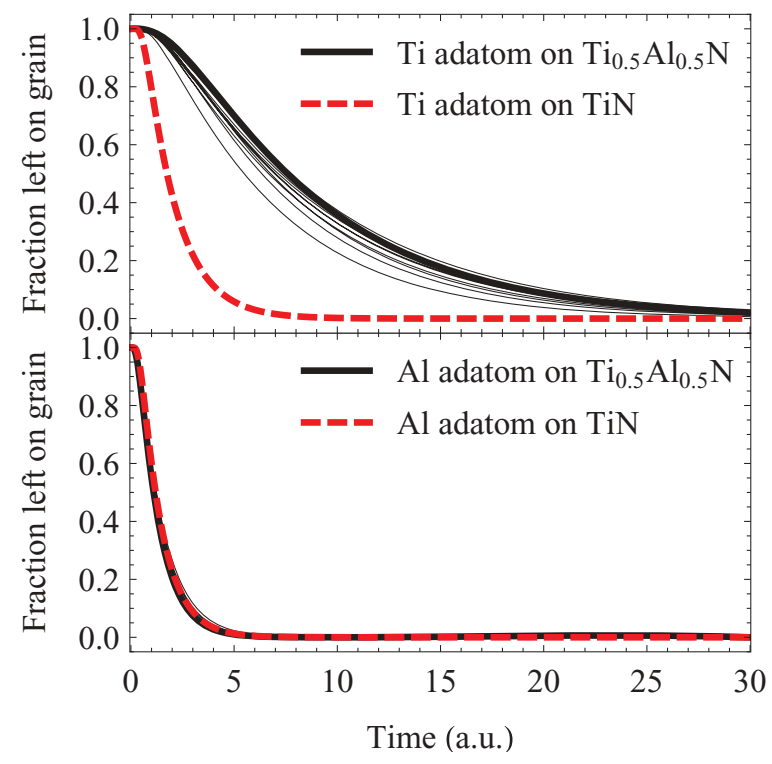

FIG. 5. (Color online) The probability as a function of time that $\mathrm{Ti}$ (upper panel) and $\mathrm{Al}$ (lower panel) adatoms placed at random positions in the center of a circular grain of radius $8.5 a_{0}$ have not reached the boundary of $\mathrm{TiN}(001)$ (red dashed line) and $\mathrm{Ti}_{0.5} \mathrm{Al}_{0.5} \mathrm{~N}(001)$ surfaces modeled with periodic $S Q S$ PES cells (thick black line) and several different surfaces modeled with randomly rotated SQS PES cells (thin black lines).

Figure 6 contains plots of $E_{\text {ads }}^{\mathrm{Al}, \mathrm{Ti}}$ relative to the most favorable adsorption site, along the preferred diffusion paths on $\mathrm{Ti}_{0.5} \mathrm{Al}_{0.5} \mathrm{~N}$ as indicated in Figs. 1(b) and 1(d). The arrows in Fig. 1 define the starting position for the energy-path plots

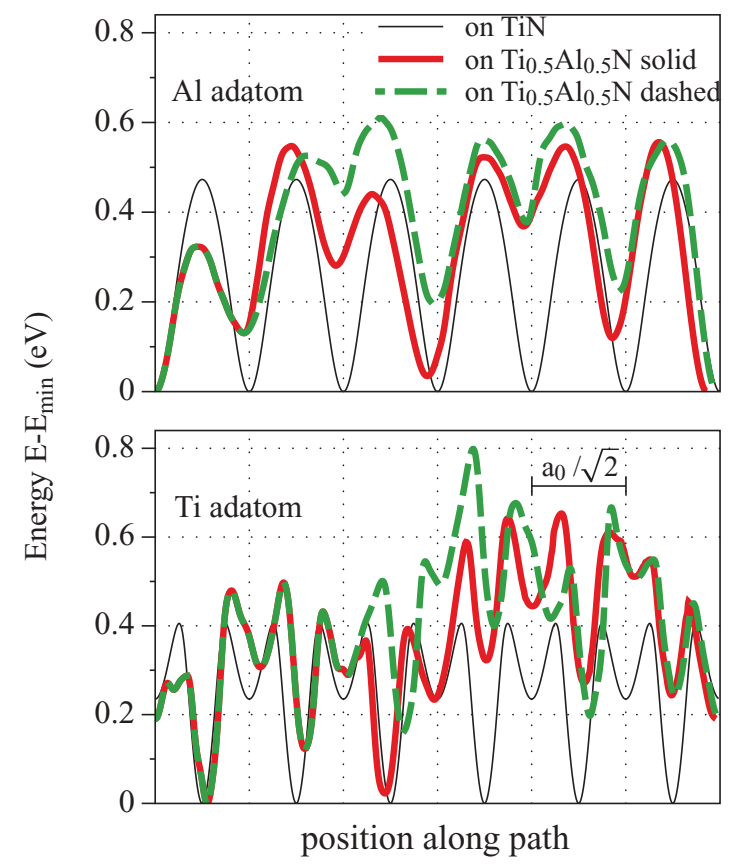

FIG. 6. (Color online) Adsorption energies of Al (upper graph) and $\mathrm{Ti}$ (lower graph) adatoms along favorable diffusion paths on ordered $\mathrm{TiN}(001)$ and disordered $\mathrm{Ti}_{0.5} \mathrm{Al}_{0.5} \mathrm{~N}(001)$ surfaces. For the disordered alloy surface, energy profiles are plotted for both the solid and dashed paths across the SQS shown in Fig. 1. 
in Fig. 6. Corresponding $E_{\text {ads }}^{\mathrm{Al}, \mathrm{Ti}}$ plots on TiN(001) are included for comparison.

The calculated $\mathrm{Al}$ adatom diffusion energy barrier on $\mathrm{TiN}(001)$ is $\Delta E_{\mathrm{TiN}}^{\mathrm{Al}}=0.47 \mathrm{eV}$. Both the solid and dashed lowenergy paths for $\mathrm{Al}$ on $\mathrm{Ti}_{0.5} \mathrm{Al}_{0.5} \mathrm{~N}(001)$ exhibit the signature of configurational disorder with alternating deep and shallow energy minima. However, the individual barrier heights are, in most cases, considerably lower on the disordered surface with the maximum energy along the outlined paths just 1.2 times larger than on the ordered $\operatorname{TiN}(001)$.

$\Delta E_{\mathrm{TiN}}^{\mathrm{Ti}}$ for Ti adatoms on $\mathrm{TiN}(001)$ is $0.40 \mathrm{eV}$ from the hollow site to the atop $\mathrm{N}$ site. The smaller barrier for migrating from the minima atop $\mathrm{N}$ to the hollow site is $0.17 \mathrm{eV}$. The individual barriers for $\mathrm{Ti}$ on $\mathrm{Ti}_{0.5} \mathrm{Al}_{0.5} \mathrm{~N}(001), \Delta E_{\mathrm{Ti}}^{\mathrm{Ti}}$, are similar, but a series of less favorable energy minima, implying a series of asymmetric jump probabilities, creates additional migration obstacles at approximately $2 / 3$ of the distance along the outlined paths. The maximum obstacles are 2.0 times and 1.6 times higher than $\Delta E_{\mathrm{TiN}}^{\mathrm{Ti}}$ on $\mathrm{TiN}(001)$ for the dashed and solid diffusion paths, respectively, explaining the dramatic reduction in mobility of $\mathrm{Ti}$ adatoms on the $\mathrm{Ti}_{0.5} \mathrm{Al}_{0.5} \mathrm{~N}(001)$ surface.

For further comparison, the energy barriers for adatom diffusion on pure $c$-AlN $(001)$ were also calculated: The $\mathrm{Al}$ adatom diffusion energy barrier $\Delta E_{\mathrm{AIN}}^{\mathrm{Al}}$ is $0.12 \mathrm{eV}$ while the diffusion energy barrier for a $\mathrm{Ti}$ adatom is $0.32 \mathrm{eV}$. Thus, the barriers for diffusion on the disordered $\mathrm{Ti}_{0.5} \mathrm{Al}_{0.5} \mathrm{~N}(001)$ surface cannot be explained as a simple mixture of $\mathrm{TiN}(001)$ and $c$-AlN $(001)$ barriers, but instead illustrate the complex effects of configurational disorder and alloying on surface diffusion.

The mass difference between $\mathrm{Al}$ and $\mathrm{Ti}$ atoms (which we ignore in these calculations) affects $v_{0}$ and will further increase the mobility difference between the two types of adatoms on the alloy surface.

Our observed decrease in $\mathrm{Ti}$ adatom mobility on $\mathrm{Ti}_{0.5} \mathrm{Al}_{0.5} \mathrm{~N}(001)$ with respect to $\mathrm{TiN}(001)$ is consistent with the experimentally reported transition in texture for polycrystalline TiN films, grown at relatively low temperatures with little or no ion irradiation, from (111) (Ref. 23) toward (001) upon alloying with AlN. ${ }^{6}$ In addition, the higher mobility of
$\mathrm{Al}$, with respect to $\mathrm{Ti}$, adatoms on $\mathrm{Ti}_{1-x} \mathrm{Al}_{x} \mathrm{~N}(001)$ provides an explanation for the results of Beckers et al. showing Al enrichment in (111)- and Al depletion in (001)-oriented grains. ${ }^{7}$ Our results also give important insight into the atomistic processes responsible for the surface-initiated spinodal decomposition observed to take place during growth of cubic-phase TiAlN by magnetron sputtering. ${ }^{9}$

\section{CONCLUSIONS}

We have compared the adsorption energy landscape and the relative mobilities of $\mathrm{Ti}$ and $\mathrm{Al}$ adatoms on ordered $\mathrm{TiN}(001)$ and disordered $\mathrm{Ti}_{0.5} \mathrm{Al}_{0.5} \mathrm{~N}(001)$ surfaces. Disordered surfaces were modeled both using a conventional SQS approach and with the global surface composed of randomly rotated SQS cells. Configurational disorder on the alloy surface results in the formation of high-energy barriers for $\mathrm{Ti}$ adatom diffusion which, together with an asymmetric adsorption energy map, dramatically reduce mobility. In contrast, $\mathrm{Al}$ adatom mobilities are nearly the same on $\mathrm{TiN}(001)$ and disordered $\mathrm{Ti}_{1-x} \mathrm{Al}_{x} \mathrm{~N}(001)$ surfaces. This is due to a much smaller disorder-induced spread in energy minima and more symmetric diffusion probability distributions along the most favorable paths on the alloy surface. These results provide important insights for understanding observed differences in preferred orientation and nanostuctural evolution during growth of polycrystalline TiN and $\mathrm{Ti}_{1-x} \mathrm{Al}_{x} \mathrm{~N}$ films.

\section{ACKNOWLEDGMENTS}

Olle Hellman and Peter Münger are acknowledged for useful discussions. We acknowledge financial support by the Swedish Foundation for Strategic Research (SSF), the Swedish Research Council (VR), and the European Research Council (ERC). The simulations were carried out using supercomputer resources provided by the Swedish National Infrastructure for Computing (SNIC) and HPC resources of SARA and PDC made available within the Distributed European Computing Initiative by the PRACE-2IP, receiving funding from the European Community's Seventh Framework Programme (FP7/2007-2013) under Grant agreement RI-283493.

\footnotetext{
*bjoal@ifm.liu.se

${ }^{1}$ H. C. Jeong and E. D. Williams, Surf. Sci. Rep. 34, 171 (1999).

${ }^{2}$ G. Antczak and G. Ehrlich, Surf. Sci. Rep. 62, 39 (2007).

${ }^{3}$ S. Kodambaka, V. Petrova, A. Vailionis, P. Desjardins, D. G. Cahill, I. Petrov, and J. E. Greene, Surf. Rev. Lett. 7, 589 (2000); S. Kodambaka, V. Petrova, S. V. Khare, D. D. Johnson, I. Petrov, and J. E. Greene, Phys. Rev. Lett. 88, 146101 (2002); S. Kodambaka, S. V. Khare, V. Petrova, D. D. Johnson, I. Petrov, and J. E. Greene, Phys. Rev. B 67, 035409 (2003); S. Kodambaka, V. Petrova, S. V. Khare, A. Vailionis, I. Petrov, and J. E. Greene, Surf. Sci. 513, 468 (2002); S. Kodambaka, S. V. Khare, I. Petrov, and J. E. Greene, Surf. Sci. Rep. 60, 55 (2006).

${ }^{4}$ M. A. Wall, D. G. Cahill, I. Petrov, D. Gall, and J. E. Greene, Phys. Rev. B 70, 035413 (2004); Surf. Sci. 581, L122 (2005).
}

${ }^{5}$ D. Gall, S. Kodambaka, M. A. Wall, I. Petrov, and J. E. Greene, J. Appl. Phys. 93, 9086 (2003).

${ }^{6}$ A. Hörling, L. Hultman, M. O. J. Sjölen, and L. Karlsson, Surf. Coat. Technol. 191, 384 (2005).

${ }^{7}$ M. Beckers, N. Schell, R. M. S. Martins, A. Mücklich, and W. Möller, J. Vac. Sci. Technol. A 23, 1384 (2005).

${ }^{8}$ I. Petrov, F. Adibi, J. E. Greene, L. Hultman, and J. E. Sundgren, Appl. Phys. Lett. 63, 36 (1993).

${ }^{9}$ F. Adibi, I. Petrov, J. E. Greene, L. Hultman, and J. E. Sundgren, J. Appl. Phys. 73, 8580 (1993).

${ }^{10}$ G. Håkansson, J.-E. Sundgren, D. McIntyre, J. E. Greene, and W. D. Münz, Thin Solid Films 153, 55 (1987); F. Adibi, I. Petrov, L. Hultman, U. Wahlström, T. Shimazu, D. McINtyre, J. E. Greene, and J. E. Sundgren, J. Appl. Phys. 69, 6437 (1991); G. Greczynski, 
J. Lu, M. Johansson, J. Jensen, I. Petrov, J. E. Greene, and L. Hultman, Vacuum 86, 1036 (2011).

${ }^{11}$ D. McIntyre, J. E. Greene, G. Håkansson, J. E. Sundgren, and W.-D. Münz, J. Appl. Phys. 67, 1542 (1990).

${ }^{12}$ H. G. Prengel, A. T. Santhanam, R. M. Penich, P. C. Jindal, and K. H. Wendt, Surf. Coat. Technol. 94-95, 597 (1997); S. PalDey and S. Deevi, Mater. Sci. Eng. A 342, 58 (2003); P. H. Mayrhofer, A. Hörling, L. Karlsson, J. Sjölén, T. Larsson, C. Mitterer, and L. Hultman, Appl. Phys. Lett. 83, 2049 (2003).

${ }^{13}$ Z. Chen, N. Kioussis, K.-N. Tu, N. Ghoniem, and J.-M. Yang, Phys. Rev. Lett. 105, 015703 (2010).

${ }^{14}$ A. V. Ruban and I. A. Abrikosov, Rep. Prog. Phys. 71, 046501 (2008).

${ }^{15}$ P. E. Blöchl, Phys. Rev. B 50, 17953 (1994).

${ }^{16}$ G. Kresse and J. Hafner, Phys. Rev. B 48, 13115 (1993).
${ }^{17}$ J. P. Perdew, K. Burke, and M. Ernzerhof, Phys. Rev. Lett. 77, 3865 (1996).

${ }^{18}$ B. Alling, M. Odén, L. Hultman, and I. A. Abrikosov, Appl. Phys. Lett. 95, 181906 (2009).

${ }^{19}$ A. Zunger, S. H. Wei, L. G. Ferreira, and J. E. Bernard, Phys. Rev. Lett. 65, 353 (1990).

${ }^{20}$ D. Sangiovanni, D. Edlund, I. Petrov, J. E. Greene, L. Hultman, and V. Chirita (unpublished).

${ }^{21}$ B. Alling, A. V. Ruban, A. Karimi, O. E. Peil, S. I. Simak, L. Hultman, and I. A. Abrikosov, Phys. Rev. B 75, 045123 (2007).

${ }^{22}$ B. Alling, A. V. Ruban, A. Karimi, L. Hultman, and I. A. Abrikosov, Phys. Rev. B 83, 104203 (2011).

${ }^{23}$ J. E. Greene, J. E. Sundgren, L. Hultman, I. Petrov, and D. B. Bergstrom, Appl. Phys. Lett. 67, 2928 (1995). 